\title{
The Study on the Influence of Highway Transportation on Regional Economic Development
}

\author{
Jun Chen", Yamei Chen",* \\ ${ }^{1}$ Guiyang Water Resources and Transportation Development Investment Group Co., Ltd., Guiyang Guizhou, \\ 550003, China \\ ${ }^{2}$ College of Civil Engineering, Guizhou University, Guiyang Guizhou, 550003, China \\ *Corresponding author
}

Keywords: Highway transportation, Regional economic development, Influence.

\begin{abstract}
Transportation industry is an important element for realizing the quality, efficiency and sustainable development of the national economy. Transportation is an important infrastructure to promote the national economy growth.. Compared with the railway transportation, waterway transportation, air transportation, highway transportation has its unique advantage. With this advantage, highway transportation plays an important role in comprehensive transportation. The development of highway transportation construction can improve the regional investment environment effectively, and can form a powerful transport stream, so as to allocate regional resources in a more reasonable way, and to promote the flow of commodities orderly, as well as to optimize the industrial structure layout and productivity layout in our country. The more robust and modernized the highway transportation system is, the greater the impact on the economic, social and ecological environment of the region will be. Highway transportation system plays an important role in promoting regional economic development.
\end{abstract}

\section{Introduction}

Highway transportation accounts for the largest part compared with other modes of transportation. Waterway transportation is limited by the river. Those inland areas with less river and water volume, the waterway transportation doesn't work. Although the air transportation is faster, it costs too much. And for those goods of great weight and volume, but of low value, will not be transported by air transportation. Railway transportation is faster than highway transportation and waterway transportation, but it is limited by the transportation lines. There are few direct vehicles. Highway develops rapidly, and these factors make highway transportation become the most direct and effective mode of transportation within the region. Since World War II, the world's highway transportation has been developing rapidly, and the highway transportation network has been improving. By the end of 2004, the total acreage of roads that our country had completed and put into use had reached up to 187.670000 hectares, and the total road freight volume reached up to 1.25 million tons, which accounts for 73 percent of the total transportation volume in the whole nation . In the field of the regional economic research, the relationship between transportation and regional economy development is a subject that the scholars at home and abroad concern a lot. However, the research on the impact of the highway transportation to regional economic development level is not enough, and it is still required much more efforts.

\section{The current situation of urban transportation development in China}

\subsection{Lacking of management and countermeasures to private motor vehicles}

With the development of economy in China, people's income has gradually increased. More and more families have small cars. The increase of vehicle makes the urban highway transportation more 
heavy. The government and relevant experts are lack of the consciousness on the prediction and management of private motor vehicles development. Many cities in our country suffer from the lag of public transportation development because of the single urban public transport management and guarantee system. Mechanized production equipment speeds up the car production, and the price of cars is lowered down. As people's economic levels are constantly improved, more and more people can afford cars. The typical public transport facilities is poor, and is crowded at the same time, which can't guarantee people's traveling,. So the number of private motor vehicles is increased, and small cars become the most commonly used tools for people's traveling.

\subsection{The immaturity of urban rail transit development}

The urban transportation closely connects to urban construction and development. The urban development and construction needs the corresponding transport system to be its backbone.

Cultural exchange, the flow of goods production, business operation, economic development and daily life are required the transportation. The modernization degree of modern transportation system is an important measurement indicator to the urban and regional economic development. Along with the deepening of reform, the economic development has also been greatly affected. The scale of urban construction and development connects to the transportation mechanism tightly. The development of motor transportation expands the urban space and population size, but the space scale and the population size does not promote the radiation function of the commercial concentrating development areas, and the radiation function of the commercial concentrating areas gradually decreases from inside to outside.

\section{The relationship between highway transportation and regional economic development}

\subsection{The mutual promotion and influence between highway transportation and regional economic development}

After the transportation meets the demand of regional economic development, the regional economy will promote the transportation. As we can see, the transportation and regional economy promote each other and influence each other. After the transportation development level and the regional economic development level have reached up to a certain degree, it will be a virtuous circle between them. Transportation will also bring adverse effect to the regional economic development. In the process of highway construction or when the highway puts into use, the release of a large number of automobile exhaust will pollute the environment, which will influence the economic growth of tourist areas within the region.

\subsection{Perfect highway transportation system can effectively promote regional economic development level}

Highway transportation and regional economic development are closely related. Under the proper conditions, if these two can promote each other and develop jointly, the development level of both will be improved. The development of highway transportation will promote the regional economic development level. For example, building and perfecting the highway transportation system, and improving its infrastructure function can effectively reduce the highway transportation costs, and improve the directness, as well as improve the regional economic advantage and competitiveness, so as to improve the overall regional economy level.

\subsection{Road transportation will improve the economic development along the highway}

After the construction of highway and transportation facilities is completed, the resources along the highway can be activated, especially the tourism resources and land resources along the highway. Transportation will change the location of the area, which will affect the value of the land. The tourism resources and land resources in the region need to be well allocated with other resources, so that their potential value can be converted into market value, and the prerequisite for allocation is the good transportation. Highway transportation construction can provide convenient conditions for the 
resources allocation, and promote the allocation between the regional tourism resources and land resources with other resources, and convert the potential value of potential resources in the area to market value.

\section{The theoretical basis of regional economic development is influenced by transportation}

\subsection{Point axis development}

As the establishment of important traffic, such as highway, railway, aviation, the river course, etc, the stream of people and logistics around main area will be increased rapidly along with the traffic trunk road opened. The production cost and transportation cost will also decrease. The favorable geographical conditions and investment environment. Will be formed around the traffic trunk road. Industries and population will concentrated along the traffic trunks. The connection area of the traffic trunk line will quickly develop into economic growth, and the area on both sides of traffic trunks is called traffic trunk axis. Through the radiation of economic growth along the axis, the economy in the whole mainland area will grow constantly. In the process of regional economic development, most of the production will be concentrated in the center of town, and the highway traffic trunk road will connect all the production points together, which will eventually forms an economy axis developed around the highway traffic trunk road.. Roads on both sides of the highway transportation trunk roads will open and radiate to the center business area, then gradually forms the industrial park, characteristic of origin, etc. The economy in the entire area will gradually improve along with the development of highway transportation trunk roads.

\subsection{Location}

Du Neng, the German economist, put forward the agricultural location theory, which emphasizes the direct contact between crop layout and the distance of the consumer market, and holds that the decisive element of the agricultural location consumption is the freight. From the perspective of this theory, the construction and development of transportation is directly linked to the development of regional economy. To the inland areas of China, especially in rural areas, highway transportation is the main mode of transportation, because the highway transportation can directly transport goods to destination quickly. With this advantage, it also saves industrial raw materials of industrial production,, transportation time and transportation cost of agricultural products, which suggests that highway traffic transportation provides convenient conditions for regional industries and agricultural economic growth.

\subsection{The increase theory of diffusion from the center to the periphery}

Fieldsman believes that the construction of the regional system is developed from the center to the periphery. There are objective differences in the distribution of production resources, production technology and market environment. After the regional space gathered develops to a certain stage, the industrial structures within the space are relatively perfect. And it will have more economic competitive advantage than those in the outlying areas, and will become the center of a regional economic system. The periphery is the space around the center region, and it is in the attachment position in regional economy system, the economic autonomy of which is low. It will gradually form to the binary structure space, as time goes by, the structure and properties of which will be strengthened. But if the highway traffic transportation system is constantly improved, the connection and communication among markets will be strengthened, and the urbanization will speed up unceasingly. The central and peripheral area will disappear. Generally speaking, the constant regional economic growth in the center area will promote the economic development in peripheral region, which will finally realize the regional economic integration. Highway transportation inland is the main link between urban and rural areas, to highway transportation The sound degree of the construction of highway transportation directly decides whether the backward rural areas can get access to investment promotion and capital introduction, and realize the export-oriented economic development. The development of highway transportation is also very important for promoting the 
coordinated development of urban and rural economy and realizing the economic integration of urban and rural areas.

\section{The influence of highway transportation on regional economic development}

\subsection{The impact of highway transportation on regional economic development}

The main function of highway transportation is to make space transfer of people and goods more quickly. The influence of highway transportation on the development of national economy mainly reflects on that the highway transportation construction can meet the needs of information and commodity circulation with the economic growth. Highway transportation is one of the basic conditions for people to survive and develop in the modern commodity economy society. Highway transportation construction and development speeds up the logistics transportation and provides a diversified flow mode for logistics, which saves a lot of cost, and greatly meets the requirements of people at different levels.

Highway traffic volume is mainly measured by passenger and freight volume. The rotation volume of passenger refers to the product of the passenger number and the distance of transportation. The freight volume is the product of the freight volume and the distance of transportation. In terms of Shaanxi province, the highway traffic volume of passengers exceeded 1 billion in 2011, and the highway traffic volume increased by 30 percent on year-on-year basis from 2009 to 2011. In 2011, the freight volume of highway traffic in Shaanxi province was more than 9 billion tons. The freight volume increased by more than 30\%. from 2009 to 2011. As we can see, the highway transportation plays an important role in people's social production and daily life, and the development of highway transportation will directly affect the development level of regional economy .

\subsection{The influence of highway transportation on regional industrial structure}

Highway transportation is classified as the tertiary industry according to the industrial nature, and the construction and development of highway transportation will increase the output value and the proportion of the tertiary industry. For several years, the proportion of tertiary industry in China has been showing the upward trend. Highway transportation will increase the liquidity of logistics and services, and will affect the industrial structure of the national economy. The improvement of highway transportation infrastructure construction and the related management measures can shorten the relative distance of transportation, and can effectively reduce transportation cost and the operation cost of enterprises. For companies, in certain cases, if the investment elements keep the same, the improvement of highway traffic can effectively reduce the production cost or increase production volume, and improve the economic benefits of enterprises,as well as attract more investment. If the highway traffic facilities are underdeveloped, it will be more difficult for the enterprise to get the investments, which severely restricts the growth of enterprises.

The development of highway transportation will optimize the industrial structure of our country, and the foundation of agriculture will be strengthened and consolidated effectively. The development of highway transportation has also promoted the urbanization construction process. The rural surplus labor force has transferred to the secondary and tertiary industries, which also makes the secondary and tertiary industries develop rapidly.

\subsection{The construction and development of highway transportation promote the balanced development of urban and rural economy within the region}

Transportation is an essential element to promote the growth factor of economy, and the main functions of highway transportation to promote the development of regional economy also reflects in the following aspects: firstly, it is effective to solve the "issues of agriculture, farmer and rural area" problem. As we all know, there are huge differences between the development of rural economy and the urban economy, and the main reason is that the rural transport facilities are worse than the urban transport facilities. The construction and development of highway transportation greatly improve the rural production and living environment, degree of industrialization in combination with the 
investment environment. Secondly, it has greatly narrowed the gap between urban and rural areas and promoted the balanced development of urbanization and regional economy. Thirdly, the construction and development of highway transportation greatly improve the resources integration around the highway and the whole region,and optimize the industrial structure reform. The construction and development of highway transportation guide the enterprises reasonable planning in fishing zones, and perfect the urban functions. It also improves the level of county area economy, and speeds up the transfer of rural surplus labor force and the process of urbanization. Attract foreign investment, and optimize the industrial structure and the layout of the productive forces, and promote the expansion of industrial resources within the region. Also improve the competitiveness of enterprises within the region. Fourthly, the construction and development of highway transportation provide powerful conditions for regional cooperation, communication, competition. And to some extent, it eliminates the regional barriers, which facilitates to build a unified and open market.

\section{Conclusion}

Highway transportation is the basic industry of the national economy, which is one of the important factors of regional economic growth. The development of highway transportation can effectively solve the problem of rapid development of regional economy. It can narrow the gap between urban and rural areas, and promote economic development in rural areas, as well as balance the regional economic development. Improve the integration of regional resources, and optimize industrial structure and productivity layout; The favorable conditions for regional competition, cooperation and exchanges will be provided, and a unified open market will be established for the region. However, there are still many problems in the development of highway transportation in China, which needs to be constantly adjusted and improved. The highway transportation department should also keep innovation and promote the development of road transportation.

\section{References}

[1] Pang Yuanhong. Maintenance status and optimization measures, Heilongjiang transportation science and technology, 2016 (03).

[2] Jizhen. Research on the quality management measures of highway subgrade construction, Heilongjiang transportation science and technology, 2014 (04).

[3] Jiang Mingju. Technical study on the pressure of road subgrade pavement in highway engineering, Heilongjiang transportation science and technology, 2014 (05).

[4] Wang Jing. Adaptive diagnostic method for highway traffic and economic development -- taking Chongqing as an example, Transportation technology and economy, 2016(02).

[5] Wang Xiaorong, Rong Chaohe, The research on the interactive development of urbanization and transportation, Economic problems exploration, 2014(01). 